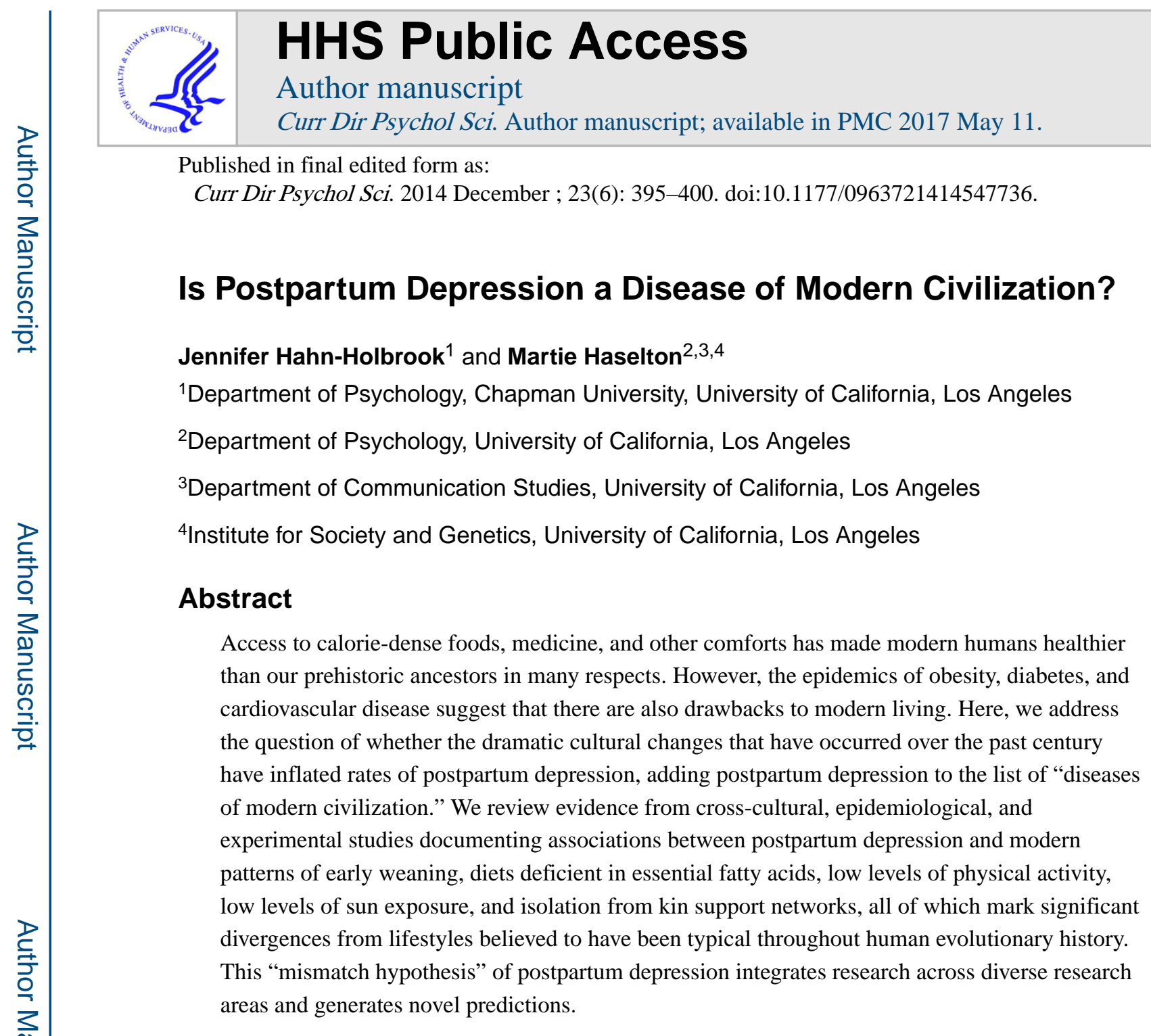

\title{
Keywords
}

postpartum depression; evolutionary medicine; omega-3 fatty acids; social support; exercise

Common maladies such as cardiovascular disease, diabetes, and even tooth cavities are rare in societies characterized by lifestyles resembling those of the human ancestral past (Gluckman \& Hanson, 2006). These "diseases of modern civilization" are thought to largely result from mismatches between the modern world and the ancient environments to which humans are adapted. Here, we propose that such a mismatch might also account for an increased prevalence of postpartum depression today.

Approximately $13 \%$ of women worldwide will experience depressive symptoms within the first 3 months postpartum (O'Hara \& Swain, 1996). Postpartum depressive symptoms result

Reprints and permissions: sagepub.com/journalsPermissions.nav

Corresponding Author: Jennifer Hahn-Holbrook, 1 University Drive, Chapman University, Orange, CA 92866, hahnholb@chapman.edu.

Declaration of conflicting interests: The authors declared that they had no conflicts of interest with respect to their authorship or the publication of this article. 
in harmful disruptions in parenting behaviors (Paulson, Dauber, \& Leiferman, 2006), which are associated with marital problems and cognitive, social, and health deficits in children (Burke, 2003). These symptoms might even lead to an increased risk of infant death (Mitchell et al., 1992). Given these dramatic costs, the simple existence of postpartum depression is an evolutionary puzzle-why does it exist at all? As we detail below, there is convergent evidence from cross-cultural, epidemiological, and experimental studies documenting associations between postpartum depression and early weaning, diets deficient in essential fatty acids, low levels of physical activity, and isolation from kin support networks, all of which are typical of modern parenting practices but were probably rare in the human evolutionary past.

In framing this mismatch hypothesis of postpartum depression, we draw on previous evolutionary-mismatch frameworks for understanding diseases of modern civilization (see Gluckman \& Hanson, 2006; Nesse \& Williams, 1996), in addition to the Pathogen Host Defense model (Raison \& Miller, 2013), which conceptualizes depressive symptoms as a biologically functional suite of sicknesslike behaviors employed to decrease activity and increase vigilance when the body's immune system is activated in response to disease or stress (Dantzer, O'Conner, Freund, Johnson, \& Kelley, 2008). Inflammation leads to signaling in the brain that can trigger the development of depressive symptoms and other sickness-like behaviors (Dantzer et al., 2008). Although there are many likely mechanisms underlying relationships between the diverse risk factors we present here and postpartum depression, a striking theme is that most have been linked to inflammatory processes during pregnancy or postpartum.

\section{Dietary Mismatches}

Although hunter-gather diets varied significantly by geography, culture, and season, scientists have pieced together a picture of the preagricultural ancestral diet from chemical analysis of human skeletal remains and archaeological excavations. From this evidence, it appears that the preagricultural human diet comprised wild meats (approximately $30 \%$ of calories), starchy tubers (approximately 30\% of calories), and seasonal fresh fruits and vegetables (approximately 30\% of calories; see Eaton, 2006, for a review). Ancestral diets tended to be richer in essential micronutrients, fiber, and fatty acids than modern Western diets (Eaton, 2006), although they were likely not necessarily better in all respects, given that periods of food shortage and caloric restriction were probably relatively common. The agricultural revolution 10,000 years ago afforded humans the potential to grow and store large quantities of energetically rich grains. Modern diets replace much of the micronutrientdense, perishable foods with grains (Eaton, 2006). This pattern has led researchers to conclude that many modern populations are overfed yet undernourished (Gluckman \& Hanson, 2006).

For example, Western diets are relatively low in omega-3 essential fatty acids (Eaton, 2006). These "good fats" make up approximately $20 \%$ of the human brain by volume, have potent anti-inflammatory effects (Simopoulos, 1991), and are prevalent in wild-caught organ meats, which were regularly consumed by preagricultural humans (Eaton, 2006). The primary protein source in Westernized countries, by contrast, is muscle meat derived from grain-fed 
livestock, which has lower levels of fat and much lower levels of omega-3 fatty acids (Eaton, 2006). Further, staple fat sources in the Western diet (e.g., dairy and vegetable oils), while rich in essential unsaturated omega- 6 fatty acids, contain little omega- 3 fatty acids. This good-fat deficit is further exacerbated by pregnancy and lactation because already-scarce maternal stores are tapped to supply the developing infant (De Vriese, Christophe, Maes, 2003). Supporting a possible link between omega-3s and postpartum depression, a recent meta-analysis aggregating results of 29 earlier randomized controlled trials showed that omega-3 fatty acid supplementation was effective as a treatment for depression (Appleton, Rogers, \& Ness, 2010).

Seafood is high in omega-3 fatty acids, and rates of postpartum depression cross-culturally are negatively related to pounds of seafood consumed per person per year (see Fig. 1). In addition, large epidemiological studies have documented negative associations between levels of circulating omega-3 fatty acids in pregnancy and risk for postpartum depression (see Markhus et al., 2013, for a review, but see Makrides et al., 2010, for a report of a small, nonsignificant reduction in postpartum depression in a randomized controlled trial of omega-3 supplementation).

Additional research is needed to address other dietary discontinuities that might impact rates of postpartum depression, including carbohydrate- and sugar-rich diets and overfeeding, which have been linked to chronic inflammation and depression outside of the context of pregnancy (Capuron et al., 2008).

\section{Breast-Feeding Mismatches}

Breast-feeding is an ancient mammalian adaptation that dramatically changes maternal hormone profiles in ways that are likely to facilitate mothers' postpartum adjustment. However, breast-feeding rates are much lower today than they were for the vast majority of human history. Stable nitrogen $\left(\delta^{15} \mathrm{~N}\right)$ and carbon $\left(\delta^{13} \mathrm{C}\right)$ isotopes unique to breast milk, which have been detected in prehistoric fossils, suggest that prehistoric infants were primarily fed breast milk for the first 1.5 years of life and were weaned sometime between 2 and 4 years of age, on average (Clayton, Sealy, \& Pfeiffer, 2006). A review of 64 small-scale societies placed weaning between the ages of 2 and 4 years, providing converging evidence of the duration of species-typical lactation for humans (Dettwyler, 1995). By contrast, in 2011, only 49\% of infants in the United States were breast-fed until 6 months of age, and approximately $20 \%$ of mothers never initiate breast-feeding at all (United States Centers for Chronic Disease Control and Prevention, 2014). Could this dramatic change in breastfeeding influence rates of postpartum depression?

Surprisingly little research has directly addressed this question, but several effects of breastfeeding provide plausible pathways through which breast-feeding could have protective effects. For example, breast-feeding releases the hormones oxytocin and prolactin, each of which have anxiolytic effects and are negatively associated with postpartum depressive symptomatology (Skrundz, Bolten, Nast, Hellhammer, \& Meinlschmidt, 2011; Zonana \& Gorman, 2005). Experimental studies in rats and correlational studies in humans have found that, compared with nonlactating mothers, lactating mothers show a reduced inflammatory 
reaction to stress (Groer \& Davis, 2006; Jaedicke, Fuhrmann, \& Stefanski, 2009). Further, breast-feeding is associated with a reduced incidence of health problems in infants and mothers over the long term, potentially leading to positive downstream consequences for maternal mental health (Hahn-Holbrook, Glynn, et al., 2013).

Consistent with these hints, in the only true experiment on breast-feeding and mood in humans, women using both breast-feeding and formula-feeding methods reported lower levels of negative affect when randomly assigned to breast-feed versus formula feed their baby in the lab (Mezzacappa \& Katlin, 2002). Further, 12 cross-sectional studies have found lower incidences of depressive symptomatology among women who breast-fed compared with woman who exclusively formula fed (see Dennis \& McQueen, 2009, for a review). From the correlational data, one cannot conclude that that breastfeeding offers mental health benefits; an alternative hypothesis seems equally plausible - that women who are depressed are simply less likely to breast-feed (Dennis \& McQueen, 2009). Recently, however, two longitudinal studies examined whether breast-feeding preceded and predicted a reduced risk of depression. These studies showed that breast-feeding fewer times per day at 3 months (Hahn-Holbrook, Glynn, et al., 2013) and weaning before 6 months (Ystrom, 2012) predicted higher risk of later postpartum depression, in line with the possibility that breastfeeding might have a protective effect (but see Dennis \& McQueen, 2007). Given the evidence, we hypothesize that modern rates of postpartum depression could partly be a consequence of mothers confronting the challenges of new motherhood without the stressregulation benefits of breast-feeding (also see Gallup, Pipitone, Carrone, \& Leadholm, 2010, for an alternative evolutionary perspective on links between breast-feeding and postpartum depression).

\section{Exercise Mismatches}

There is little doubt that modern humans, particularly in the West, get less exercise than did ancestral humans. The introduction of mechanized farming technologies, for example, reduced the total basal metabolic demands of farm workers by 50\% in Japan and 65\% in Britain (Eaton, Eaton, \& Konnor, 1997). Moreover, contemporary hunter-gathers burn an estimated 3,000 calories a day, as compared with 2,000 calories a day for U.S. adults (Eaton et al., 1997).

Exercise acts on multiple pathways thought to influence depression, including chronic inflammation, insulin resistance, and serotonergic and dopaminergic activity (Lucassen et al., 2010). Moreover, these biological systems undergo dramatic changes during pregnancy and lactation (Elenkov et al., 2001), which raises the possibility that exercise-induced regulation of these systems might be even more important during the postpartum transition. Consistent with this view, a meta-analysis of five randomized controlled trials showed that exercise interventions reduced rates of postpartum depression, compared with non-active treatment or social support (Daley, Jolly, \& MacArthur, 2009). This result echoed results from a larger meta-analysis of 11 studies documenting decreases in general clinical depression after exercise interventions (Stathopoulou, Powers, Berry, Smits, \& Otto, 2006). 


\section{Sun-Exposure Mismatches}

The primary source of vitamin D synthesis in humans is sun exposure, yet modern humans are increasingly sheltered from the sun. This discontinuity has led to an epidemic of vitamin D deficiency (Dawodu \& Wagner, 2007). Eighteen percent of pregnant woman in the United Kingdom, 25\% in the United Arab Emirates, $42 \%$ in northern India, $61 \%$ in New Zealand, $45 \%$ of African American women in the United States, and $60 \%$ to $84 \%$ of non-Western women in the Netherlands are deficient in circulating levels of vitamin D (Dawodu \& Wagner, 2007). Shortfalls in vitamin D are exacerbated by the nutritional demands of pregnancy and lactation, which has led to outbreaks of rickets among some breast-fed U.S. infants (Arora \& Hobel, 2010).

Vitamin D acts on the immune system by stimulating antimicrobial responses that suppress inflammation (Arora \& Hobel, 2010). Hence, vitamin D deficiency during pregnancy increases mothers' susceptibility to infections and inflammation (Arora \& Hobel, 2010), potentially leading to postpartum depression. Consistent with this notion, a cross-sectional study of 176 pregnant African American women found that vitamin D deficiency was associated with depressive symptoms (Cassidy-Bushrow, Peters, Johnson, Li, \& Rao, 2012). Although no vitamin D intervention studies of depression in pregnancy or postpartum have yet been conducted, a double-blind randomized controlled trial in overweight adults showed that vitamin D supplementation significantly reduced depressive symptoms, and a metaanalysis of correlational studies documented a similar association (Anglin, Samaan, Walter, \& McDonald, 2013).

\section{Child Care Mismatches}

Hunter-gather families typically live in kin groups in which grandparents, aunts and uncles, and older siblings assist mothers and fathers with their young children (Burkart, Hrdy, \& Van Schaik, 2009). In contrast, in the Western world, nuclear families often live hundreds or thousands of miles away from close kin. Further, Western families have fewer children spaced closer together in age, simultaneously making it less likely that older siblings will be available to help with child care and more likely that mothers will need to simultaneously care for multiple very young children. A meta-analysis documented that weak or absent social support was one of the most consistent predictors of postpartum depression (O'Hara \& Swain, 1996). Therefore, it is plausible that the shift from multigenerational families to smaller nuclear families might impact women's ability to cope with the demands of motherhood.

The "Latina paradox" provides additional suggestive evidence. The paradox is that mothers who emigrate from Mexico to the United States have lower rates of postpartum depression than White mothers, even though immigrant mothers are relatively disadvantaged economically and are more often unmarried (Campos et al., 2008). The factor thought to explain this paradox is the high degree of family and community support experienced by Latina women, compared with richer but more isolated White women (Campos et al., 2008). Further, in a longitudinal study of 210 women from diverse economic and ethnic backgrounds, maternal support from family, but not the baby's father, buffered mothers 
against increases in the stress hormone placental corticotropin-releasing factor in pregnancy, reducing their risk for postpartum depression (Hahn-Holbrook, Dunkel Schetter, Chander, \& Hobel, 2013).

Nannies, babysitters, and daycare centers can help take the place of extended-family child care networks. However, these solutions are expensive and might not be able to replace the emotional support provided by family that is important for maternal coping postpartum.

\section{Other Risk Factors}

The evidence for the mismatch hypothesis is compelling and could help explain the relatively high rates of postpartum depression in many modern populations. However, there are additional predictors of postpartum depression that might not be more common today than they were in the ancestral past, including chronic life stress, father abandonment, infant health problems, and history of depression. These factors are likely to have other etiological relationships with postpartum depression and different evolutionary foundations than the associations we have described (see Hagen, 1999, for an evolutionary perspective on postpartum depression that incorporates these risk factors). In sum, the mismatch hypothesis of postpartum depression is an important—if incomplete-account for cases of postpartum depression.

\section{Conclusion}

The mismatch hypothesis of postpartum depression can serve as a guide for future research. For example, one prediction stemming from this hypothesis is that rates of postpartum depression will vary across cultures because of differences in breast-feeding, traditional diets, active lifestyles, daily sun exposure, and the presence of kin. Further, although there is substantial evidence of associations between a variety of modern factors and increased risk for postpartum depression, more research is needed to establish causal relationships and to develop and test potential interventions. Some interventions suggested here, such as vitamin $\mathrm{D}$ and omega-3 fatty acid supplementation, are promising because of their simplicity. This framework also suggests that some advice given to pregnant women-for example, to avoid sun exposure (to prevent skin cancer) and limit fish consumption (because of mercury exposure) — might put them at risk of postpartum depression. Other interventions, such as increasing breast-feeding and exercise, might be more challenging to implement because of multiple, competing demands on women today. Our hope is that the mismatch-hypothesis framework will trigger additional research and identify interventions that will enhance outcomes for mothers and their children.

\section{Recommended Reading}

Dantzer R, O'Connor JC, Freund GG, Johnson RW, Kelley KW. From inflammation to sickness and depression: When the immune system subjugates the brain. Nature Reviews Neuroscience. 2008; 9:46-56. An overview of the role of inflammation in the etiology of depression. [PubMed: 18073775]

Hahn-Holbrook, J., Dunkel Schetter, C., Haselton, M. The advantages and disadvantages of breastfeeding for maternal mental and physical health. In: Spiers, M.Geller, P., Kloss, J., editors. 
Women's health psychology. New York, NY: Wiley; 2013. p. 414-439.A book chapter summarizing what we know about the mental-health ramifications of breastfeeding for mothers

Hidaka BH. Depression as a disease of modernity: Explanations for increasing prevalence. Journal of Affective Disorders. 2012; 140:205-214. A related article describing the rise in rates of major depressive disorder as a function of modern living. [PubMed: 22244375]

Hrdy, SB. Mothers and others: The evolutionary origins of mutual understanding. Cambridge, MA: Belknap Press; 2009. An accessible book that discusses the important role that kin and other group members likely played in raising offspring throughout human evolutionary history

Nesse RM, Williams GC. A classic book outlining evolutionary approaches to understanding human disease. 1996 See References.

\section{References}

Anglin RE, Samaan Z, Walter SD, McDonald SD. Vitamin D deficiency and depression in adults: Systematic review and meta-analysis. The British Journal of Psychiatry. 2013; 202:100-107. [PubMed: 23377209]

Appleton KM, Rogers PJ, Ness AR. Updated systematic review and meta-analysis of the effects of n-3 long-chain polyunsaturated fatty acids on depressed mood. The American Journal of Clinical Nutrition. 2010; 91:757-770. [PubMed: 20130098]

Arora CP, Hobel CJ. Vitamin D—a novel role in pregnancy. Biopolymers \& Cell. 2010; 26:97-104.

Burkart JM, Hrdy SB, Van Schaik CP. Cooperative breeding and human cognitive evolution. Evolutionary Anthropology: Issues, News, and Reviews. 2009; 18:175-186.

Burke L. The impact of maternal depression on familial relationships. International Review of Psychiatry. 2003; 15:243-255. [PubMed: 15276963]

Campos B, Schetter CD, Abdou CM, Hobel CJ, Glynn LM, Sandman CA. Familialism, social support, and stress: Positive implications for pregnant Latinas. Cultural Diversity \& Ethnic Minority Psychology. 2008; 14:155-162. [PubMed: 18426288]

Capuron L, Su S, Miller AH, Bremner JD, Goldberg J, Vogt GJ, et al. Vaccarino V. Depressive symptoms and metabolic syndrome: Is inflammation the underlying link? Biological Psychiatry. 2008; 64:896-900. [PubMed: 18597739]

Cassidy-Bushrow AE, Peters RM, Johnson DA, Li J, Rao DS. Vitamin D nutritional status and antenatal depressive symptoms in African American women. Journal of Women's Health. 2012; 21:1189-1195.

Clayton F, Sealy J, Pfeiffer S. Weaning age among foragers at Matjes River Rock Shelter, South Africa, from stable nitrogen and carbon isotope analyses. American Journal of Physical Anthropology. 2006; 129:311-317. [PubMed: 16323185]

Daley A, Jolly K, MacArthur C. The effectiveness of exercise in the management of post-natal depression: Systematic review and meta-analysis. Family Practice. 2009; 26:154-162. [PubMed: 19126829]

Dantzer R, O'Conner JC, Freund GG, Johnson RW, Kelley KW. From inflammation to sickness and depression: When the immune system subjugates the brain. Nature Reviews Neuroscience. 2008; 9:46-56. [PubMed: 18073775]

Dawodu A, Wagner CL. Mother-child vitamin D deficiency: An international perspective. Archives of Disease in Childhood. 2007; 92:737-740. [PubMed: 17715433]

Dennis CL, McQueen K. Does maternal postpartum depressive symptomatology influence infant feeding outcomes? Acta Paediatrica. 2007; 96:590-594. [PubMed: 17391475]

Dennis CL, McQueen K. The relationship between infant-feeding outcomes and postpartum depression: A qualitative systematic review. Pediatrics. 2009; 123:e736-e751. DOI: 10.1542/peds. 2008-1629 [PubMed: 19336362]

Dettwyler, KA. A time to wean: The hominid blueprint for the natural age of weaning in modern human populations. In: Stuart-Macadam, P., Dettwyler, KA., editors. Breastfeeding: Biocultural perspectives. Hawthorne, NY: Aldine de Gruyter; 1995. p. 39-73. 
De Vriese SR, Christophe AB, Maes M. Lowered serum n-3 polyunsaturated fatty acid (PUFA) levels predict the occurrence of postpartum depression: Further evidence that lowered n-PUFAs are related to major depression. Life Sciences. 2003; 73:3181-3187. [PubMed: 14561523]

Eaton SB. The ancestral human diet: What was it and should it be a paradigm for contemporary nutrition? Proceedings of the Nutrition Society. 2006; 65:1-6.

Eaton SB, Eaton SB, Konnor MJ. Paleolithic nutrition revisited: A twelve-year retrospective on its nature and implications. European Journal of Clinical Nutrition. 1997; 51:207-216. [PubMed: 9104571]

Elenkov IJ, Wilder RL, Bakalov VK, Link AA, Dimitrov MA, Fisher S, et al. Chrousos GP. IL-12, TNF-a, and hormonal changes during late pregnancy and early postpartum: Implications for autoimmune disease activity during these times. Journal of Clinical Endocrinology \& Metabolism. 2001; 86:4933-4938. [PubMed: 11600565]

Gallup GG Jr, Pipitone NR, Carrone KJ, Leadholm KL. Bottle-feeding simulates child loss: Postpartum depression and evolutionary medicine. Medical Hypotheses. 2010; 74:174-176. [PubMed: 19666213]

Gluckman, P., Hanson, M. Mismatch: Why our world no longer fits our bodies. New York, NY: Oxford University Press; 2006.

Groer MW, Davis MW. Cytokines, infections, stress, and dysphoric moods in breastfeeders and formula feeders. Journal of Obstetric, Gynecologic, \& Neonatal Nursing. 2006; 35:599-607.

Hagen EH. The functions of postpartum depression. Evolution \& Human Behavior. 1999; 20:325-359.

Hahn-Holbrook J, Dunkel Schetter C, Chander A, Hobel C. Placental corticotropin-releasing hormone mediates the association between prenatal social support and postpartum depression. Clinical Psychological Science. 2013; 1:253-265. [PubMed: 23997996]

Hahn-Holbrook J, Glynn L, Haselton M, Dunkel Schetter C. Does breastfeeding offer protection against maternal depressive symptomatology? A prospective study from pregnancy to two years after birth. Archives of Women's Mental Health. 2013; 16:411-422.

Hibbeln JR. Seafood consumption, the DHA content of mothers' milk and prevalence rates of postpartum depression: A cross-national, ecological analysis. Journal of Affective Disorders. 2002; 69:15-30. [PubMed: 12103448]

Jaedicke KM, Fuhrmann MD, Stefanski V. Lactation modifies stress-induced immune changes in laboratory rats. Brain, Behavior, and Immunity. 2009; 23:700-708.

Lucassen PJ, Meerlo P, Naylor AS, Van Dam AM, Dayer AG, Fuchs E, et al. Czeh B. Regulation of adult neurogenesis by stress, sleep disruption, exercise and inflammation: Implications for depression and antide-pressant action. European Neuropsychopharmacology. 2010; 20:1-17. [PubMed: 19748235]

Makrides M, Gibson RA, McPhee AJ, Yelland L, Quinlivan J, Ryan P. Effect of DHA supplementation during pregnancy on maternal depression and neurodevelopment of young children: A randomized controlled trial. Journal of the American Medical Association. 2010; 304:1675-1683. [PubMed: 20959577]

Markhus MW, Skotheim S, Graff IE, Frøyland L, Braarud HC, Stormark KM, Malde MK. Low omega-3 index in pregnancy is a possible biological risk factor for postpartum depression. PLoS ONE. 2013; 8(7):e67617. Retrieved from http://www.plosone.org/article/info\%3Adoi \%2F10.1371\%2Fjournal.pone.0067617. [PubMed: 23844041]

Mezzacappa ES, Katlin ES. Breast-feeding is associated with reduced perceived stress and negative mood in mothers. Health Psychology. 2002; 21:187-193. [PubMed: 11950109]

Nesse, RM., Williams, GC. Why we get sick: The new science of Darwinian medicine. New York, NY: Vintage Books; 1996.

Mitchell EA, Thompson JMD, Stewart AW, Webster ML, Taylor BJ, Hassall IB, et al. Becroft DMO. Postnatal depression and SIDS: A prospective study. Journal of Paediatrics and Child Health. 1992; 28:13-16.

O'Hara M, Swain A. Rates and risk of postpartum depression: A meta-analysis. International Review of Psychiatry. 1996; 8:37-54.

Paulson JF, Dauber S, Leiferman JA. Individual and combined effects of postpartum depression in mothers and fathers on parenting behaviors. Pediatrics. 2006; 118:659-668. [PubMed: 16882821] 
Raison CL, Miller AH. The evolutionary significance of depression in Pathogen Host Defense (PATHOS-D). Molecular Psychiatry. 2013; 18:15-37. [PubMed: 22290120]

Simopoulos AP. Omega- 3 fatty acids in health and disease and in growth and development. The American Journal of Clinical Nutrition. 1991; 54:438-463. [PubMed: 1908631]

Skrundz M, Bolten M, Nast I, Hellhammer DH, Meinlschmidt G. Plasma oxytocin concentration during pregnancy is associated with development of postpartum depression. Neuropsychopharmacology. 2011; 36:1886-1893. [PubMed: 21562482]

Stathopoulou G, Powers MB, Berry AC, Smits AJ, Otto MW. Exercise interventions for mental health: A quantitative and qualitative review. Clinical Psychological Science in Practice. 2006; 13:179-93.

United States Centers for Chronic Disease Prevention and Health Promotion. Breastfeeding report card 2014. Washington, D.C.: Centers for Disease Control and Prevention; 2014.

Ystrom E. Breastfeeding cessation and symptoms of anxiety and depression: A longitudinal cohort study. BMC Pregnancy Childbirth. 2012; 12:12-36. [PubMed: 22390254]

Zonana JE, Gorman JM. The neurobiology of postpartum depression. CNS Spectrums. 2005; 10:792799. [PubMed: 16400241] 


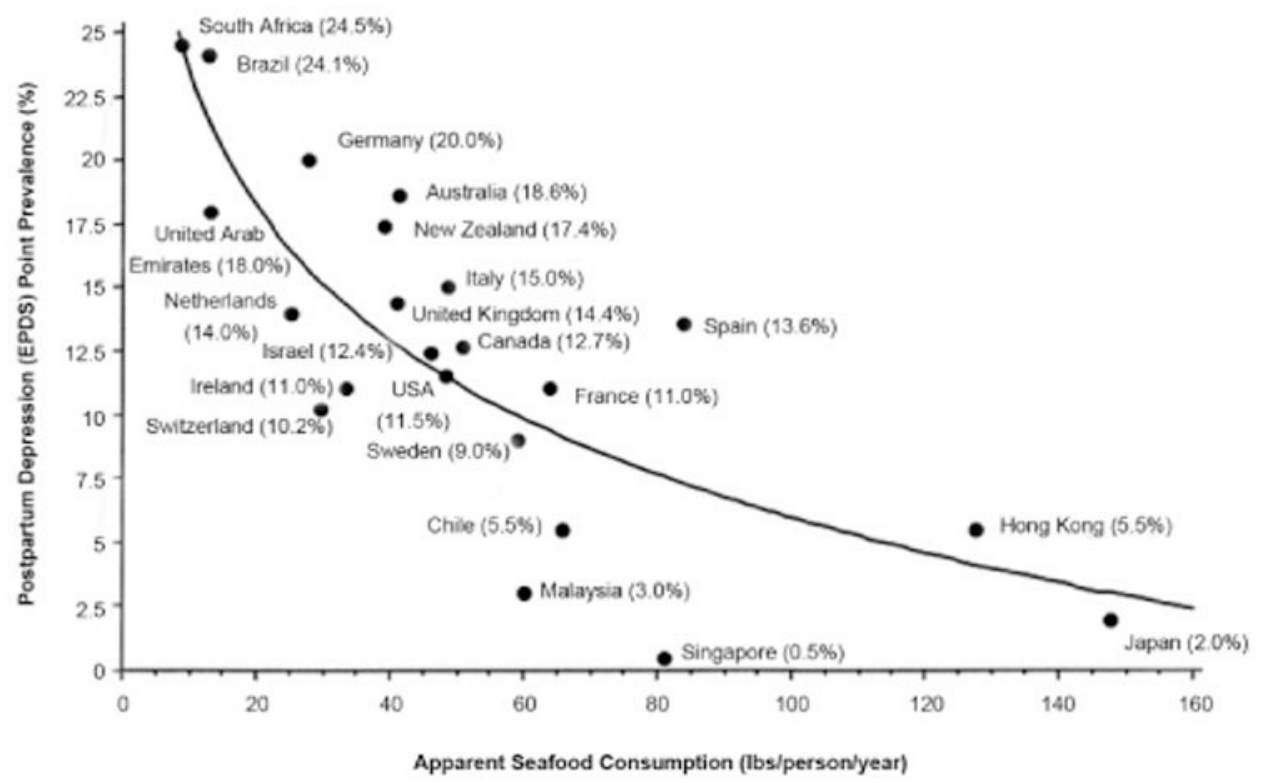

Fig. 1.

Cross-national rates of postpartum depression as a function of seafood consumption. The graph shows the inverse correlation between apparent seafood consumption (in pounds per person, per year; calculated by adding the country's yearly seafood catch and imports minus its exports) and prevalence of postpartum depression by country. This association remained significant after adjusting for gross domestic product and after removing outlying Asian nations. EPDS = Edinburgh Postpartum Depression Scale. Reprinted from "Seafood Consumption, the DHA Content of Mothers' Milk and Prevalence Rates of Postpartum Depression: A Cross-National, Ecological Analysis," by J. R. Hibbeln, 2002, Journal of Affective Disorders, 69, p. 22 Copyright 2002 by Elsevier. Reprinted with permission. 